OPEN ACCESS

Edited by:

Jean-Marc Olivot,

Centre Hospitalier Universitaire de

Toulouse, France

Reviewed by:

Aristeidis H. Katsanos,

University of loannina, Greece

Birgitta Johansson,

University of Gothenburg, Sweden

*Correspondence:

Yannick Béjot

yannick.bejot@chu-dijon.fr

Specialty section:

This article was submitted to

Stroke,

a section of the journal

Frontiers in Neurology

Received: 14 June 2019 Accepted: 12 August 2019 Published: 28 August 2019

Citation:

Graber M, Garnier L, Duloquin G, Mohr S, Guillemin S, Ramaget O, Piver A, Tainturier C, Bret-Legrand C,

Delpont B, Blanc-Labarre C,

Guéniat J, Hervieu-Bègue M, Osseby G-V, Giroud M and Béjot Y (2019) Association Between Fatigue and Cognitive Impairment at 6 Months in Patients With Ischemic Stroke Treated With Acute Revascularization Therapy. Front. Neurol. 10:931. doi: 10.3389/fneur.2019.00931

\section{Association Between Fatigue and Cognitive Impairment at 6 Months in Patients With Ischemic Stroke Treated With Acute Revascularization Therapy}

Mathilde Graber, Lucie Garnier, Gauthier Duloquin, Sophie Mohr, Sophie Guillemin, Océane Ramaget, Ariane Piver, Cécile Tainturier, Christine Bret-Legrand, Benoit Delpont, Christelle Blanc-Labarre, Julien Guéniat, Marie Hervieu-Bègue, Guy-Victor Osseby, Maurice Giroud and Yannick Béjot*

\section{Dijon Stroke Registry, EA7460, Pathophysiology and Epidemiology of Cerebro-Cardiovascular diseases (PEC2), University} Hospital of Dijon, University of Burgundy, Dijon, France

Background: Fatigue is a frequent symptom after stroke. We aimed to determine the association between fatigue and cognitive performance in patients with ischemic stroke who received acute revascularization therapy (IV thrombolysis and/or mechanical thrombectomy).

Methods: Seventy patients were prospectively included in the stroke unit of the University Hospital of Dijon, France. A follow-up was performed at 6 months with clinical examination, fatigue assessment by the Fatigue Severity Scale (FSS), and a comprehensive neuropsychological evaluation. Patients with fatigue (FSS score $>4$ ) were compared with patients without fatigue. Neuropsychological factors associated with fatigue at 6 months were analyzed using multivariable logistic regression models.

Results: Fatigue was reported by $34.3 \%$ of patients. Patients with fatigue were older, had more frequent residual handicap, depressive symptoms, and impaired quality of life. They had more frequently low score $(<26)$ on the MoCA scale $(79.2$ vs. $47.8 \%$, OR = 4.15; 95\% Cl: 1.32-13, $p=0.015$ ), memory impairment (60 vs. 30.6\%, OR = 3.41; 95\% Cl: 1.09-10.7, $p=0.035$ ), and executive dysfunction (65 vs. 30.8\%, OR = 4.18; $95 \% \mathrm{Cl}: 1.33-13.1, p=0.014)$. In multivariable logistic regression analysis, only memory impairment was independently associated with fatigue (OR =5.70; 95\% Cl: 1.09-29.6, $p$ $=0.039)$. Further analyses restricted to non-depressed patients $(n=58,84.1 \%)$ showed in multivariable models that a score $<26$ on MoCA scale (OR 5.12; 95\% Cl: 1.00-26.2, $p=0.05)$, and a memory impairment (OR $=6.17$; 95\% Cl: 1.06-35.9, $p=0.043$ ) were associated with fatigue. There was also a non-significant trend toward an association between divided attention deficit and fatigue (OR $=6.79 ; 95 \% \mathrm{Cl}$ : 0.80-57.6, $p=0.079$ ). 
Conclusion: The association between fatigue and subtle cognitive impairment including memory or attention deficits could be of interest in elaborating future interventional studies to evaluate the impact of therapeutic strategies, including cognitive rehabilitation, on fatigue.

Keywords: stroke, ischemic stroke, fatigue, cognitive impairment, outcome, depression

\section{INTRODUCTION}

Ischemic stroke has beneficiated from major therapeutic advances over the past 20 years, leading to improvements in patients' survival and motor outcome. Consequently, several previously neglected post-stroke complications have emerged as important concerns affecting quality of life. Fatigue is a major complaint of patients after ischemic stroke. Fatigue is a subjective, multidimensional experience, with perceptualmotor, emotional and cognitive components, making it difficult to define and measure. Objective fatigue, defined as an observable and measurable decrease in performance that occurs during the repetition of a mental or physical activity, can be distinguished from subjective fatigue, defined as a feeling of exhaustion, weakness, and aversion to effort (1). For Staub and Bogousslavsky, it is a reversible decrease or loss of ability, associated with an intense feeling of physical and/or mental overwork, even in the absence of special effort, and a pronounced feeling of exhaustion that disrupts or makes it impossible to perform routine activities (2).

The prevalence of fatigue after ischemic stroke ranges between 29 and $77 \%$ in the literature (3). Several reasons can explain these inconsistent estimates such as the use of various scales for assessment, various time points after stroke for evaluation, differences in population settings, and characteristics of patients including residual motor disability, chronic pain, sleep disorders, and depression, that may influence post-stroke fatigue (4). Fatigue can persist long after the onset of the cerebral infarction and has a negative impact in terms of survival, recovery, and be associated with a profound deterioration in several aspects of daily life (family, social, and professional) (5).

Although it is the subject of a growing literature, the exact mechanisms underlying post-stroke fatigue have not yet been fully elucidated. Some pathophysiological studies carried out on various neurological diseases suggest that primary fatigue could be linked to damage in neural networks, particularly reticular formation and attention network (6-9). Surprisingly, while cognitive impairment is a major complication after stroke (10), there is few data on its association with fatigue. Indeed, a very limited number of studies focusing on poststroke fatigue incorporated cognitive assessment of patients, and assessments were most often based on global tests or limited to a few areas of cognition, thus making conclusions uncertain (11).

Therefore, the aim of this study was to investigate the prevalence of fatigue 6 months after ischemic stroke and its association with cognitive performances in patients who received acute revascularization therapy.

\section{METHODS}

\section{Study Population}

This observational prospective cohort study was conducted at the Stroke Unit of the University Hospital of Dijon, France (Study Registration Number 2017-A01906-47; Clinical Trial Number NCT03288090). This study received approval from the national ethics committee (CPP SUD-EST 4). All patients gave their oral consent to participate according to the French legislation.

Patients $\geq 18$ years old who suffered hemispheric acute ischemic stroke defined according to the WHO criteria and confirmed by imaging (CT-scan or MRI) who received a revascularization therapy (intravenous thrombolysis and/or mechanical thrombectomy) according to current recommendations were included between August 2017 and May 2018. Exclusions criteria were major co-morbidities prior to ischemic stroke that may be responsible for significant fatigue, previous dementia or aphasia, persistence of severe aphasia, or severe disability (modified Rankin scale score $>$ 3) at 6 months preventing a reliable cognitive assessment. Because of the exploratory nature of this study in the absence of previous reliable data in ischemic stroke patients treated with acute revascularization therapy, no sample size calculation was performed.

\section{Data Collected, Patients' Follow-Up, and Outcomes Measured}

At inclusion following data were collected: demographics, vascular risk factors including hypertension (high blood pressure recorded in a patient's medical history or patients under antihypertensive treatment), diabetes mellitus (reported in the medical record or patients taking insulin or oral hypoglycemic agents), hypercholesterolemia (reported in the medical history or patients treated with lipid-lowering therapy), current smoking, history of coronary heart disease, atrial fibrillation, excessive alcohol consumption (defined as alcohol intake $\geq 3$ units a day in men and $\geq 2$ in women). Stroke severity at onset was evaluated using the National Institutes of Health Stroke Scale (NIHSS) score.

Patients were evaluated face-to-face by a senior neurologist at 6 months. Clinical examination included evaluation of the NIHSS score, and functional handicap using the modified Rankin Score (mRS). Fatigue was evaluated by the Fatigue Severity Scale (FSS) (12). This scale includes 9 items rated from 1 to 7 , assessing physical fatigue, the impact of fatigue on the psychosocial environment and fatigue in general ( 3 items in each category). Each item is a quote for which patients are asked to judge the application for themselves of "strongly disagree" (1 point) to 
"strongly agree" (7 points). The total score therefore varies from 9 to 63 . The average of the total score is calculated by dividing the total score by the number of items to which the patient has responded. This average defines the FSS score, which ranges from 1 to 7 . Patients with a score $>4$ were considered as having fatigue in accordance with the literature (13). A vertical visual numerical scale for fatigue assessment was also performed in addition to the FSS scale (rated from 0 to 100 on a $10 \mathrm{~cm}$ scale). Anxiety and depression were rated using the Hospital Anxiety Depression scale (HAD). A score $>7$ for either anxiety or depression was retained as significant (14). Global pain and quality of life were rated on a vertical numerical scale (rated from 0 to 100 on a $10 \mathrm{~cm}$ scale). A sleep assessment was also performed using the Pittsburgh Sleep Quality Index (PSQI). A total score $>5$ was considered to reflect sleep disturbances.

A comprehensive neuropsychological assessment was performed by a neuropsychologist according to the GRECoGVASC battery $(15,16)$, a French-language adaptation and standardization of the National Institute of Neurological Disorders and Stroke-Canadian Stroke Network comprehensive battery (17). Several cognitive domains were explored: visuospatial and visuoconstructive skills assessed by the Rey Figure, episodic memory (verbal and visual) evaluated by the RL/RI-16 test [French adaptation of the Free and Cued Selective Reminding Test of Gruber and Buschke (18)] for the verbal modality and memory reproduction of the Rey figure for the visual modality (19), executive functions evaluated by the Trail Making Test (TMT) (20), the Subtest of Codes from Wechsler adult intelligence scale (WAIS-IV) (21), and the Verbal Fluences (categorical and lexical) (22). To assess divided attention, the computerized double task divided attention test of the Test of Attentional Performance (TAP) was administered to patients
(23). Working memory was also tested using the Corsi cubes test and the serial span test taken from the Wechsler Memory Scale (MEM III) (24). Finally, global cognitive function was evaluating by the Montreal Cognitive Assessment scale (MoCA) (25).

The results of the neuropsychological evaluation were dichotomized into two groups (normal or abnormal). The standards chosen were defined according to the GREFEX (French Focus Group on Executive Functions Assessment) standards for the evaluation of executive functions (22), and the GREMEM (French Focus Group on Memory Assessment) standards for the evaluation of memory functions (26). These norms are stratified on age and socio-cultural level. Concerning the interpretation of the tests from the MEM III and WAIS-IV scales, the pathological thresholds were defined on the basis of standard scores, stratified on age. Working memory and/or information processing speed were considered abnormal if a standard score was $\leq 5$ for one of the scores in each event. The pathological threshold for the divided attention test was $\leq 10$ th percentile for the number of omissions, as used in clinical practice. Patients were considered to have executive functions impairment if they had an abnormal test in at least one of the following domains: mental flexibility, fluences, working memory, or processing speed.

\section{Statistical Analysis}

Categorical variables were presented as frequencies, and quantitative variables were summarized as mean \pm standard deviation (SD), or median (interquartile interval, IQR) values. Two groups of patients were considered: patients who had significant fatigue at 6 months (FSS scale $>4$ ) vs. patients without fatigue. Characteristics of patients were compared between groups using the Chi-2 test or exact Fisher test for categorical variables, and the Wilcoxon- Mann-Whitney test for quantitative

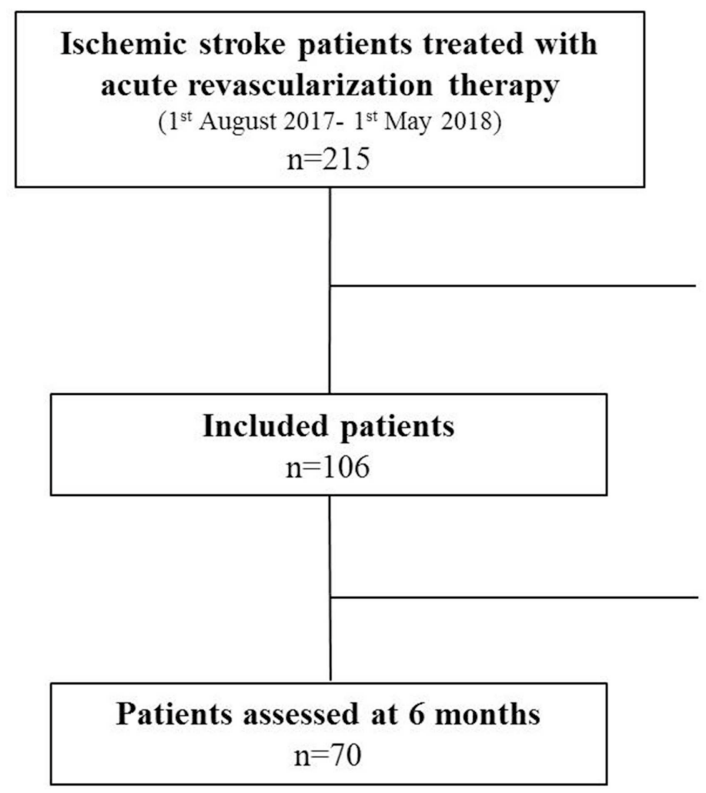

Not included patients $(n=109)$ :

No consent to participate or exclusion criteria

Excluded patients $(n=36)$ :

Withdrawal of consent $(\mathrm{n}=18)$

Severe residual handicap $(\mathrm{n}=11)$

Stroke recurrence $(n=4)$

Death $(\mathrm{n}=2)$

Loss of follow-up $(n=1)$

FIGURE 1 | Flowchart of the study. 
TABLE 1 | Characteristics of patients according to fatigue at 6 months.

\begin{tabular}{|c|c|c|c|c|c|}
\hline & \multicolumn{2}{|c|}{$\begin{array}{c}\text { No fatigue } \\
N=46(65.7 \%)\end{array}$} & \multicolumn{2}{|c|}{$\begin{array}{c}\text { Fatigue } \\
N=24(34.3 \%) \\
\end{array}$} & \multirow[t]{2}{*}{$\boldsymbol{P}$} \\
\hline & $N$ & $\%$ & $N$ & $\%$ & \\
\hline Age, mean \pm SD & \multicolumn{2}{|c|}{$63.3 \pm 14.7$} & \multicolumn{2}{|c|}{$70.3 \pm 13.1$} & 0.04 \\
\hline Age, median (IQR) & \multicolumn{2}{|c|}{63 (54-73) } & \multicolumn{2}{|c|}{75 (64-78) } & \\
\hline Male gender & 30 & 65.2 & 11 & 45.8 & 0.12 \\
\hline \multicolumn{6}{|l|}{ Medical history } \\
\hline Diabetes & 7 & 15.2 & 3 & 12.5 & 0.53 \\
\hline Hypertension & 24 & 52.2 & 15 & 62.5 & 0.41 \\
\hline Hypercholesterolemia & 12 & 26.1 & 12 & 50.0 & 0.045 \\
\hline Coronary heart disease & 6 & 13.0 & 1 & 4.2 & 0.23 \\
\hline Atrial fibrillation $\$$ & 10 & 22.2 & 6 & 25.0 & 0.80 \\
\hline Current smoker & 14 & 30.4 & 5 & 20.8 & 0.39 \\
\hline Alcohol consumption & 8 & 17.4 & 2 & 8.3 & 0.26 \\
\hline Premorbid mRS score $<2$ & 43 & 93.5 & 23 & 95.8 & 0.58 \\
\hline $\begin{array}{l}\text { NIHSS score at onset, } \\
\text { median (IQR) }\end{array}$ & \multicolumn{2}{|c|}{$8(5-14)$} & \multicolumn{2}{|c|}{$10(5-15)$} & 0.69 \\
\hline $\begin{array}{l}\text { Acute revascularization } \\
\text { therapy }\end{array}$ & & & & & 0.30 \\
\hline IV thrombolysis only & 26 & 56.5 & 10 & 41.7 & \\
\hline $\begin{array}{l}\text { Mechanical thrombectomy } \\
\text { only }\end{array}$ & 8 & 17.4 & 8 & 33.3 & \\
\hline Combined therapy & 12 & 26.1 & 6 & 25.0 & \\
\hline Stroke side & & & & & 0.32 \\
\hline Right & 18 & 39.1 & 13 & 54.2 & \\
\hline Left & 25 & 54.4 & 11 & 45.8 & \\
\hline Bilateral & 3 & 6.5 & 0 & 0 & \\
\hline \multicolumn{6}{|l|}{ Outcomes at 6 months } \\
\hline mRS score & & & & & 0.014 \\
\hline mRS 0-1 & 33 & 71.7 & 10 & 41.7 & \\
\hline$m R S \geq 2$ & 13 & 28.3 & 14 & 58.3 & \\
\hline NIHSS score $=0$ & 37 & 80.4 & 14 & 58.3 & 0.048 \\
\hline Anxiety & 12 & 26.7 & 8 & 33.3 & 0.56 \\
\hline Depressive symptoms & 4 & 8.9 & 7 & 29.2 & 0.028 \\
\hline $\begin{array}{l}\text { Depressive symptoms or } \\
\text { antidepressant }\end{array}$ & 8 & 17.8 & 10 & 41.7 & 0.031 \\
\hline Sleep disturbances & 19 & 43.2 & 16 & 66.7 & 0.06 \\
\hline Pain, mean $\pm \mathrm{SD}^{\dagger}$ & \multicolumn{2}{|c|}{$22.8 \pm 22.1$} & \multicolumn{2}{|c|}{$33.3 \pm 24.5$} & 0.07 \\
\hline Pain, median $(\mathrm{IQR})^{\dagger}$ & \multicolumn{2}{|c|}{$20(0-35)$} & \multicolumn{2}{|c|}{$40(7-50)$} & \\
\hline Quality of life, mean $\pm \mathrm{SD}^{\dagger}$ & \multicolumn{2}{|c|}{$72.33 \pm 15.43$} & \multirow{2}{*}{\multicolumn{2}{|c|}{$\begin{array}{l}56.67 \pm 19.87 \\
50(47.5-67.5)\end{array}$}} & $<0.01$ \\
\hline Quality of life, median (IQR) & \multicolumn{2}{|c|}{$75(65-80)$} & & & \\
\hline
\end{tabular}

\$Previously known or diagnosed during hospitalization.

${ }^{\dagger}$ Numerical vertical scale.

variables. Logistic regression models were used to evaluate factors associated with fatigue at 6 months. In multivariate analyses, confounding variables with a $p<0.10$ were introduced into the final models. A sub-group analysis was performed in non-depressed patients. Statistical analysis was performed with STATA@13 software (StataCorp LP, College Station, Texas, USA).

\section{RESULTS}

\section{Prevalence of Fatigue and Patients' Characteristics}

Of the 215 patients admitted for acute ischemic stroke who received a revascularization therapy between August 2017 and
TABLE 2 | Factors independently associated with fatigue at 6 months in multivariable logistic regression analysis.

\begin{tabular}{lcc}
\hline & OR $\mathbf{( 9 5 \% ~ C l )}$ & $\boldsymbol{P}$ \\
\hline Hypercholesterolemia & $2.83(1.0-7.98)$ & 0.049 \\
mRS score $\geq 2$ & $3.55(1.26-10.0)$ & 0.016 \\
Depressive symptoms & $4.22(1.09-16.3)$ & 0.037 \\
Quality of life $^{\dagger}$ & $0.95(0.92-0.98)$ & 0.002 \\
\hline
\end{tabular}

OR, Odd ratios.

${ }^{\dagger}$ Numerical vertical scale.

TABLE 3 | Proportion of patients who performed neuropsychological tests in fatigue and no fatigue groups.

\begin{tabular}{|c|c|c|c|c|c|}
\hline & \multicolumn{2}{|c|}{$\begin{array}{c}\text { No fatigue } \\
N=46(65.7 \%)\end{array}$} & \multicolumn{2}{|c|}{$\begin{array}{c}\text { Fatigue } \\
N=24(34.3 \%)\end{array}$} & \multirow[t]{2}{*}{$P$} \\
\hline & $N$ & $\%$ & $N$ & $\%$ & \\
\hline RL/RI-16 & 39 & 84.8 & 21 & 87.5 & 0.76 \\
\hline Rey figure copy & 39 & 84.8 & 21 & 87.5 & 0.76 \\
\hline Rey figure memory reproduction & 36 & 78.3 & 18 & 75.0 & 0.76 \\
\hline TMT & 41 & 89.1 & 21 & 87.5 & 0.84 \\
\hline Subtest of Codes (WAIS-IV) & 40 & 87.0 & 20 & 83.3 & 0.68 \\
\hline Verbal Fluences & 40 & 87.0 & 21 & 87.5 & 0.95 \\
\hline Working memory (MEM III) & 38 & 82.6 & 19 & 79.2 & 0.73 \\
\hline TAP & 36 & 78.3 & 15 & 62.5 & 0.16 \\
\hline MOCA & 46 & 100 & 24 & 100 & 1.00 \\
\hline
\end{tabular}

May 2018, 106 were initially included. Among these patients, 70 were finally assessed at 6 months (59\% men, mean age: $65.7 \pm$ 14.5 years). Reasons for exclusion of patients were withdrawal of consent during follow-up $(n=18)$, severe residual handicap not compatible with a neuropsychological evaluation $(n=11)$, stroke recurrence $(n=4)$, death $(n=2)$, or loss of follow-up $(n=1)$ (Figure 1).

All patients responded to all items of the FSS. There was a good correlation between FSS score and score on fatigue vertical numerical scale (Spearman coefficient: $0.66, p<0.001$ ). Twentyfour patients $(34.3 \%)$ reported significant fatigue (defined as FSS score $>4)$. Characteristics of patients according to fatigue are shown in Table 1. Patients who reported fatigue were older (70.3 \pm 13.1 vs. $63.3 \pm 14.7 p=0.04$ ), and had more frequently hypercholesterolemia, depressive symptoms (29.2 vs. $8.9 \%, p=$ 0.028 ), and residual handicap ( $\mathrm{mRS}$ score $\geq 2$ : $58.3 \%$ vs. $28.3, p$ $=0.014)$. In addition, patients with fatigue had worse quality of life on the vertical numerical scale [Median score: 50 (47$67)$ vs. 75 (65-80), $p=0.0005$ ]. In multivariable analysis, factors associated with significant fatigue at 6 months were a history of hypercholesterolemia, the presence of depressive symptoms on the HAD scale, mRS score $\geq 2$ and, lower score on quality of life scale (Table 2).

\section{Neuropsychological Evaluation and Fatigue at 6 Months}

There was no difference in the proportion of patients who were administered neuropsychological tests according to fatigue at 6 


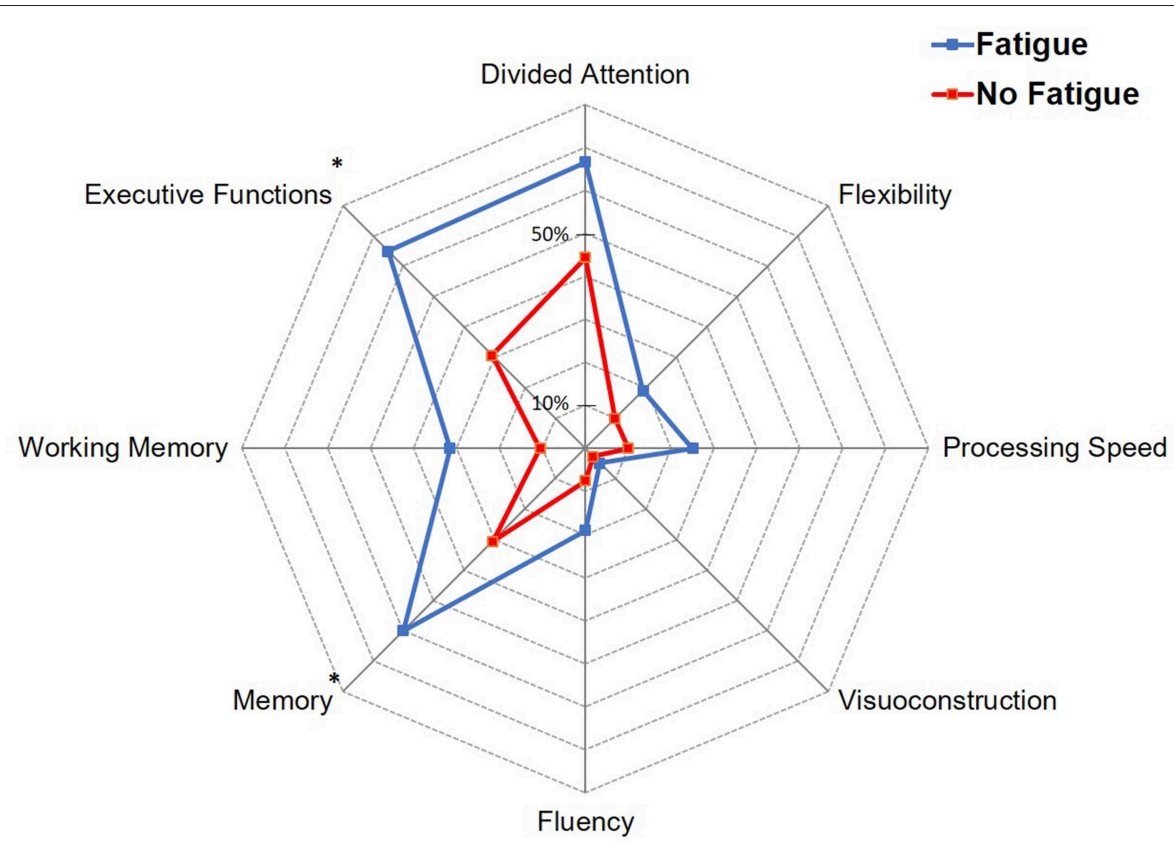

FIGURE 2 | Proportion of patients with impairment in the different cognitive domains according to fatigue. ${ }^{*} p<0.05$.

TABLE 4 | Association between fatigue at 6 months and each neuropsychological variable in overall patients and non-depressed patients in multivariable logistic regression analyses.

\begin{tabular}{|c|c|c|c|c|c|}
\hline & Tests used & \multicolumn{2}{|c|}{ Overall patients } & \multicolumn{2}{|c|}{ Non-depressed patients } \\
\hline Memory impairment & $\begin{array}{l}\text { RL/RI-16 } \\
\text { Rey figure } \\
\text { memory reproduction }\end{array}$ & $5.70(1.09-29.6)$ & 0.039 & $6.17(1.06-35.9)$ & 0.043 \\
\hline Processing speed impairment & $\begin{array}{l}\text { TMT part A } \\
\text { Subtest of Codes (WAIS-IV) }\end{array}$ & $2.16(0.33-13.9)$ & 0.419 & $1.77(0.25-12.6)$ & 0.567 \\
\hline Mental flexibility impairment & TMT part B & $1.83(0.32-10.6)$ & 0.501 & $3.24(0.39-26.8)$ & 0.275 \\
\hline Fluences impairment & Verbal Fluences & $1.11(0.13-9.52)$ & 0.925 & $1.49(0.15-14.9)$ & 0.735 \\
\hline
\end{tabular}

OR, odd ratios.

\$Adjusted for age, sex, mRS score, sleep disturbances, pain, and depression.

${ }^{*}$ Adjusted for age, sex, mRS score, sleep disturbances and pain.

${ }^{\dagger}$ Defined as impairment in mental flexibility, fluences, working memory, or processing speed.

months (Table 3). A higher proportion of patients with a low score on the MoCA scale (score $<26$ ) was observed in patients with fatigue compared with patients without fatigue $(79.2$ vs. $47.8 \%, \mathrm{OR}=4.15 ; 95 \% \mathrm{CI}: 1.32-13, p=0.015)$. Figure 2 shows the proportion of patients with abnormal scores on the different cognitive domains according to fatigue. A higher proportion of patients with fatigue had memory impairment ( 60 vs. $30.6 \%$, OR $=3.41$; 95\% CI: $1.09-10.7, p=0.035$ ), and executive dysfunction defined as impairment of either working memory, processing speed, fluency or mental flexibility (65 vs. $30.8 \%$, OR $=4.18$;
95\% CI: $1.33-13.1, p=0.014)$. In multivariable logistic regression analysis, memory impairment was the only cognitive variable independently associated with fatigue at 6 months $(\mathrm{OR}=5.70$; 95\% CI: 1.09-29.6, $p=0.039$; Table 4).

Further analyses were restricted to the subgroup of nondepressed patients ( $n=58,84.1 \%$ of the total cohort). Among these patients, $41(70.7 \%)$ had significant fatigue at 6 months. A higher proportion of patients with fatigue had a low score on MoCA scale (82.3 vs. $43.9 \% p=0.07$; OR $=5.96$; $95 \%$ CI $1.48-$ $24.0, p=0.012$ ). Figure 3 shows the proportion of non-depressed 


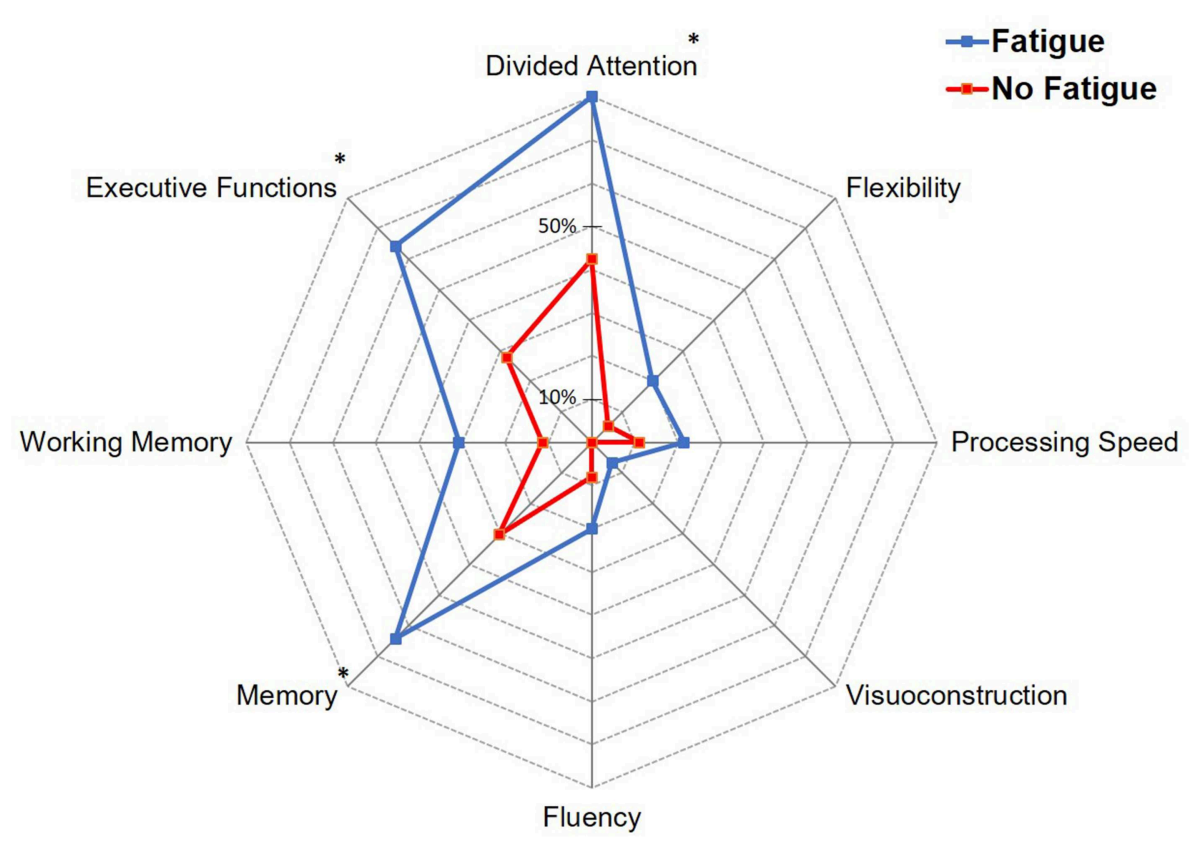

FIGURE 3 | Proportion of non-depressed patients with impairment in the different cognitive domains according to fatigue. ${ }^{*} p<0.05$.

patients with abnormal scores in the different cognitive domains according to fatigue. Patients with fatigue had more frequently memory impairment (64.3 vs. $30.3 \%$; OR $=4.14$; $95 \%$ CI: $1.10-$ $15.5, p=0.035$ ), executive dysfunction (64.3 vs. $27.8 \%$; OR $=$ 4.68; 95\% CI: $1.26-17.4, p=0.021)$, or deficit in divided attention task ( 80 vs. $42.4 \%$; OR $=5.43$; $95 \%$ CI: $1.00-29.6, p=0.051)$. In multivariable logistic regression analysis, a score $<26$ on MoCA scale (OR 5.12; 95\% CI: 1.00-26.2, $p=0.05$ ) and a memory impairment $(\mathrm{OR}=6.17$; 95\% CI: $1.06-35.9, p=0.043)$ were associated with fatigue at 6 months in non-depressed patients. In addition, there was a non-significant trend toward an association between divided attention deficit and fatigue $(\mathrm{OR}=6.79 ; 95 \% \mathrm{CI}$ : $0.80-57.6, p=0.079)$.

\section{DISCUSSION}

This study demonstrated that fatigue is a common symptom 6 months after ischemic stroke in patients who received acute revascularization therapy. Indeed, nearly a third of patients had significant fatigue. The frequency of fatigue observed in our population is nevertheless rather low when we consider the wide distribution of the prevalence of fatigue in epidemiological studies in which up to $77 \%$ of patients may suffer this symptom (4). Since fatigue is correlated with residual motor disability, the observed difference could be explained by the fact that our population was composed of patients with a low residual disability $(72.9 \%$ of patients had a NIHSS $=0$ score and $61.4 \%$ had a mRs score $\leq 1)$. A study conducted in patients with minor ischemic stroke (initial NIHSS score $\leq 6$ and 6-month mRs score $\leq 1$ ) found a prevalence of fatigue of $30 \%$, which is consistent with our results (27). To account for the relationship between fatigue and residual handicap, it could be argue that physical activity is more important in patients with a good motor recovery thus improving fatigue through different mechanisms including aerobic training that could strengthen muscle capacity and allow better physical performance by reducing the feeling of fatigue. Physical exercise could also contribute to higher self-esteem and more social interaction (28).

Depression appears to be closely associated with fatigue. In our study $29 \%$ of patients with fatigue had depressive symptoms, which is consistent with previous studies (29). Fatigue has long been considered a symptom of post-stroke depression. Although fatigue and depression are closely related, it is now recognized that fatigue can exist independently of depression. Indeed, fatigue after ischemic stroke can occur in the absence of depression, which has also been highlighted in other neurological diseases including Parkinson's disease (30), and multiple sclerosis (31). The question remains open regarding the causal relationships between depression and fatigue: depression may in some cases be more a consequence than a causal factor of fatigue (32). Although patients with fatigue were older than those without fatigue, we did not find a significant statistical correlation between age and FSS score (Spearman coefficient: $0.11, p=0.39$ ). In the literature, the association between post-stroke fatigue and age has been inconsistently reported (4).

The presence of cognitive impairment appears to be associated with fatigue. Considering that depression may influence cognitive evaluations, we studied a subgroup of non-depressed patients. As a result, a low score on MoCA scale was associated with fatigue in non-depressed patients. Several studies did not report association between fatigue and cognitive impairment (33). This may be explained by the fact that these studies used the Mini-Mental State Examination (MMSE) score that have a lower sensitivity than the MoCA in assessing post-stroke cognitive 
impairment (34). Indeed, unlike the MMSE score, the MoCA scale allows an assessment of executive and attentional functions, which are frequently affected in vascular cognitive disorders.

When analyzing specifically cognitive domains, memory impairment was significantly associated with fatigue in both overall and non-depressed patients. One previous study found more frequent memory problems in patients with post-stroke fatigue compared with those without fatigue (35). Conversely, two studies did not conclude to such an association, but neuropsychological tests used for memory assessment differed from our study $(27,36)$. In addition, only minor strokes for one study and both minor strokes and transient ischemic attacks for the other were included. We also found a trend toward an association between fatigue and divided attention impairment in non-depressed patients, although statistical significance was not reached probably due to a lack of power. To the best of our knowledge, one study found an association between sustained attention deficit and fatigue 1 year after ischemic stroke, as well as with executive disorders in a group of non-depressed patients (27). Another study found attention deficit but in a more heterogeneous population that also involved patients with subarachnoid hemorrhage (37). Several studies have shown a correlation between impaired processing speed and fatigue after stroke (35-37). However, in one study, the deficit was only detected at 3 and did not persist after 6 months, the other two studies did not specify when the neuropsychological assessment was performed during follow-up.

Cognitive impairment has been shown to contribute to fatigue after subarachnoid hemorrhage (38) or traumatic brain injury (39). Our study would reinforce the idea that this may also be the case for ischemic stroke. If cognitive disorders and fatigue appear to be related, it is difficult to specify causal links. Ischemic stroke is an interesting condition for understanding major cognitive functions due to possible focal lesion. Some so-called strategic lesions have helped to establish neuroanatomical correlates of cognitive functions. Regarding fatigue, a pilot study conducted in patients with ischemic stroke who had no significant sequelae or mood disorders found that brainstem and thalamic lesions were more frequent in patients with fatigue (40). The authors suggested that so-called primary fatigue could be the result of minimal attention deficits secondary to an interruption of neural networks, particularly the reticular formation. This hypothesis was not confirmed by a subsequent study conducted in a larger number of patients, in which no association between fatigue and the side or site of the lesion was found (27). Since fatigue is a multidimensional and complex phenomenon, any injury can contribute to increasing the risk of fatigue due to its multiple expression.

Several limitations must be acknowledged. Despite a large screening, the number of patients finally included was limited, thus leading to a lack of power for some multivariable analyses. In a few cases, it was not possible to perform several neuropsychological tests, but there was no difference between patients with and those without fatigue. These limitations underline the fact that neuropsychological assessment after stroke, as well as evaluation of other functional outcomes including fatigue, is difficult and time consuming in routine clinical practice, which could explain the paucity of data in the literature. Finally, it was not possible to assess with the FSS which specific dimension of fatigue the patients complained with. Hence, it would be interesting to evaluate whether cognitive impairment could be more frequently observed in patients with mental fatigue rather than physical fatigue.

To conclude, fatigue after ischemic stroke is a frequent symptom even in patients treated with acute revascularization therapies and good functional recovery. Although it is difficult to establish a causal link, the association between fatigue and subtle cognitive impairment including memory or attention deficits could be of interest in developing further interventional studies so as to define therapeutic strategies to improve these symptoms.

\section{DATA AVAILABILITY}

The datasets generated for this study are available on request to the corresponding author.

\section{AUTHOR CONTRIBUTIONS}

MGr: study concept and design, acquisition of data, neurological evaluation of patients, analysis and interpretation of data, and drafting and revising the manuscript for content. LG, GD, SM, BD, CB-La, JG, MH-B, G-VO, and MGi: acquisition of data, neurological evaluation of patients, and critical revision of manuscript for intellectual content. SG, OR, AP, CT, and CB-Le: acquisition of data, neuropsychological evaluation of patients, and critical revision of manuscript for intellectual content. YB: study concept and design, acquisition of data, neurological evaluation of patients, analysis and interpretation of data, study supervision, obtaining funding, drafting, and revising the manuscript for content.

\section{FUNDING}

This study was supported by the University Hospital of Dijon, the Dijon Stroke Registry (Registre Dijonnais des AVC), and ADNSB (Association pour le Développement des Neurosciences en Bourgogne).

\section{ACKNOWLEDGMENTS}

We thank Lucile Dubourget, Nathalie Mielle, Florence Dubois, Corinne Chevalier, Pascale Raclot, Héloïse Brunet, and Jérôme Durier for their assistance, and the patients and their families for their participation. 


\section{REFERENCES}

1. Staub F, Bogousslavsky J. Post stroke depression or fatigue. Eur Neurol. (2001) 45:3-5. doi: 10.1159/000052081

2. Staub F, Bogousslavsky J. Fatigue after stroke: a major but neglected issue. Cerebrovasc Dis. (2001) 12:75-81. doi: 10.1159/0000 47685

3. Acciarresi M, Bogousslavsky J, Paciaroni M. Post-stroke fatigue: epidemiology, clinical characteristics and treatment. Eur Neurol. (2014) 72:255-61. doi: 10.1159/000363763

4. Lerdal A, Bakken LN, Kouwenhoven SE, Pedersen G, Kirkevold M, Finset A, Kim HS. Poststroke fatigue-a review. J Pain Symptom Manage. (2009) 38:928-49. doi: 10.1016/j.jpainsymman.200 9.04.028

5. Glader EL, Stegmayr B, Asplund K. Postroke fatigue: a 2-year follow-up study of stroke patients in Sweden. Stroke. (2002) 33:1327-33. doi: 10.1161/01.STR.0000014248.28711.D6

6. Van Zomeren AH, Brouwer WH, Deelman BG. Attentional deficits: the riddles of selectivity, speed and alertness. In: D Brooks, editor. Closed Head Injury: Psychological, Social and Family Consequences. Oxford: Oxford University Press (1984). p. 398-415.

7. Bruno R, Creange S, Frick N. Parallels between post-polio fatigue and chronic fatigue syndrome: a common pathophysiology? Am J Med. (1998) 105:6673. doi: 10.1016/S0002-9343(98)00161-2

8. Colombo B, Martinelli Boneschi F, Rossi P, Rovaris M, Maderna L, Filippi $\mathrm{M}$, et al. MRI and motor evoked potential findings in nondisabled multiple sclerosis patients with and without symptoms of fatigue. J Neurol. (2000) 247:506-9. doi: 10.1007/s004150070148

9. Chaudhuri A, Behan P. Fatigue and basal ganglia. J Neurol Sci. (2000) 179:3442. doi: 10.1016/S0022-510X(00)00411-1

10. Pendlebury ST, Rothwell PM. Oxford Vascular Study. Incidence and prevalence of dementia associated with transient ischaemic attack and stroke: analysis of the population-based Oxford Vascular Study. Lancet Neurol. (2019) 18:248-58. doi: 10.1016/S1474-4422(18)30442-3

11. Lagogianni C, Thomas S, Lincoln N. Examining the relationship between fatigue and cognition after stroke: a systematic review. Neuropsychol Rehabil. (2016) 28:57-116. doi: 10.1080/09602011.2015.1127820

12. Krupp LB, LaRocca NG, Muir-Nash J, Steinberg AD. The fatigue severity scale. Application to patients with multiple sclerosis and systemic lupus erythematosus. Arch Neurol. (1989) 46:1121-3. doi: 10.1001/archneur.1989.00520460115022

13. Whitehead L. The measurement of fatigue in chronic illness: a systematic review of unidimensional and multidimensional fatigue measures. $J$ Pain Symptom Manage. (2009) 37:107-28. doi: 10.1016/j.jpainsymman.200 7.08.019

14. Whelan-Goodinson R, Ponsford J, Schonberger M. Validity of the hospital anxiety and depression scale to assess depression and anxiety following traumatic brain injury as compared with the structured clinical interview for DSM-IV. J Affect Dis. (2009) 114:94-102. doi: 10.1016/j.jad.200 8.06.007

15. Godefroy O, Yaïche H, Taillia H, Bompaire F, Nédélec-Ciceri C, Bonnin $\mathrm{C}$, et al. Who should undergo a comprehensive cognitive assessment after a stroke? A cognitive risk score. Neurology. (2018) 91:e197987. doi: 10.1212/WNL.0000000000006544

16. Godefroy O, Leclercq C, Roussel M, Moroni C, Quaglino V, Beaunieux H, et al. GRECOG-VASC Neuropsychological Committee. French adaptation of the vascular cognitive impairment harmonization standards: the GRECOGVASC study. Int J Stroke. (2012) 7:362-3. doi: 10.1111/j.1747-4949.2012.0 0794.x

17. Hachinski V, Iadecola C, Petersen RC, Breteler MM, Nyenhuis DL, Black SE, et al. National institute of neurological disorders and strokecanadian stroke network vascular cognitive impairment harmonization standards. Stroke. (2006) 37:2220-4. doi: 10.1161/01.STR.0000237236.88 823.47

18. Grober E, Buschke H. Genuine memory deficits in dementia. Dev Neuropsychol. (1987) 3:13-36. doi: 10.1080/87565648709540361
19. Rey A. [The psychological examination in cases of traumatic encepholopathy. Problems]. Arch Psychol. (1941) 28:215-85.

20. Tombaugh TN. Trail making test $\mathrm{A}$ and $\mathrm{B}$ : normative data stratified by age and education. Arch Clin Neuropsychol. (2004) 19:203-14. doi: 10.1016/S0887-6177(03)0 0039-8

21. Wechsler D. WAIS-IV Administration and Scoring Manual (Wechsler Adult Intelligence Scale - Fourth Edition) Pearson, 4th Edn. (2008). p. 258

22. Godefroy O. Groupe de Réflexion pour l'Evaluation des Fonctions Exécutives (GREFEX). In: O. Godefroy, editor. Fonctions exécutives et Pathologies Neurologiques et Psychiatriques: Evaluation en Pratique Clinique. Louvain-laNeuve, De Boeck Université (2015). p. 312.

23. Zimmermann P, Fimm B. A test battery for attentional performance. In: M. Leclercq and P. Zimmermann, editors. Applied Neuropsychology of Attention: Theory, Diagnosis and Rehabilitation. New York, NY: Psychology Press (2002). p. 110-51.

24. Weschler D. MEM-III, Échelle Clinique de Mémoire de Wechsler. Paris: les Éditions du Centre de psychologie appliquée (2001). p. 449.

25. Nasreddine ZS, Phillips NA, Bédirian V, Charbonneau S, Whitehead V, Collin I, et al. The montreal cognitive assessment, MoCA: a brief screening tool for mild cognitive impairment. J Am Geriatr Soc. (2005) 53:6959. doi: 10.1111/j.1532-5415.2005.53221.x

26. Van der Linden M. Groupe de Réflexion sur l'Evaluation de la Mémoire (GREMEM) Lévaluation des Troubles de la Mémoire. Solal (2004). p. 101.

27. Radman N, Staub F, Aboulafia-Brakha MA, Berney A, Bogousslavsky J, Annoni JM. Poststroke fatigue following minor infarcts: a prospective study. Neurology. (2012) 79:1422-7. doi: 10.1212/WNL.0b013e3182 $6 \mathrm{~d} 5 \mathrm{f} 3 \mathrm{a}$

28. Duncan F, Lewis SJ, Greig CA, Dennis MS, Sharpe M, MacLullich AM, et al. Exploratory longitudinal cohort study of associations of fatigue after stroke. Stroke. (2015) 45:1052-8. doi: 10.1161/STROKEAHA.114.0 08079

29. Ingles JL, Eskes GA, Phillips SJ. Fatigue after stroke. Arch Phys Med Rehabil. (1999) 80:173-8. doi: 10.1016/S0003-9993(99)90116-8

30. Friedman J, Friedman H. Fatigue in parkinson's disease. Neurology. (1993) 43:2016-19. doi: 10.1212/WNL.43.10.2016

31. van der Werf SP, Jongen PJ, Lycklama À, Nijeholt GJ, Barkhof F, Hommes OR, et al. Fatigue in multiple sclerosis: interrelations between fatigue complaints, cerebral MRI abnormalities and neurological disability. J Neurol Sci. (1998) 160:164-70. doi: 10.1016/S0022-510X(98)00251-2

32. Van der Werf SP, Van der Broek HLP, Anten HWM, Bleijenberg G. Experience of severe fatigue long after stroke and its relation to depressive symptoms and disease characteristics. Eur Neurol. (2001) 45:28-33. doi: 10.1159/000052085

33. Ponchel A, Bombois S, Bordet R, Hénon H. Factors associated with poststroke fatigue: a systematic review. Stroke Res Treat. (2015) 2015:347920. doi: 10.1155/2015/347920

34. Lees R, Selvarajah J, Fenton C, Pendlebury ST, Langhorne P, Stott DJ, et al. Test accuracy of cognitive screening tests for diagnosis of dementia and multidomain cognitive impairment in stroke. Stroke. (2014) 45:300818. doi: 10.1161/STROKEAHA.114.005842

35. Pihlaja R, Uimonen J, Mustanoja S, Tatlisumak T, Poutiainen E. Poststroke fatigue is associated with impaired processing speed and memory functions in first-ever stroke patients. J Psychosom Res. (2014) 77:3804. doi: 10.1016/j.jpsychores.2014.08.011

36. Maaijwee NA, Arntz RM, Rutten-Jacobs LC, Schaapsmeerders P, Schoonderwaldt HC, van Dijk EJ, et al. Post-stroke fatigue and its association with poor functional outcome after stroke in young adults. J Neurol Neurosurg Psychiatr. (2015) 86:1120-6. doi: 10.1136/jnnp-2014-308784

37. Johansson B, Rönnbäck L. Mental fatigue and cognitive impairment after an almost neurological recovered stroke. ISRN Psychiatr. (2012) 2012:686425. doi: 10.5402/2012/686425

38. Passier PE, Post M, Van Zandvoort MJ, Rinkel GJ, Lindeman E, Visser-Meily JM. Predicting fatigue 1 year after aneurysmal subarachnoid hemorrhage. $J$ Neurol. (2011) 258:1091-7. doi: 10.1007/s00415-010-5891-y 
39. Dimoska-Di Marco A, McDonald S, Kelly M, Tate R, Johnstone S. A meta-analysis of response inhibition and Stroop interference control deficits in adults with traumatic brain injury (TBI). J Clin Exp Neuropsychol. (2011) 33:471-85. doi: 10.1080/13803395.2010.5 33158

40. Staub F, Annoni JM, Bogousslavsky J. Fatigue after stroke: a pilot study. Cerebrovasc Dis. (2000) 10(Suppl 2):62. doi: 10.1002/p ri. 476

Conflict of Interest Statement: YB received honoraria for or consulting fees from AstraZeneca, Bayer, BMS, Pfizer, Medtronic, MSD, Amgen, and BoehringerIngelheim.
The remaining authors declare that the research was conducted in the absence of any commercial or financial relationships that could be construed as a potential conflict of interest.

Copyright (c) 2019 Graber, Garnier, Duloquin, Mohr, Guillemin, Ramaget, Piver, Tainturier, Bret-Legrand, Delpont, Blanc-Labarre, Guéniat, Hervieu-Bègue, Osseby, Giroud and Béjot. This is an open-access article distributed under the terms of the Creative Commons Attribution License (CC BY). The use, distribution or reproduction in other forums is permitted, provided the original author(s) and the copyright owner(s) are credited and that the original publication in this journal is cited, in accordance with accepted academic practice. No use, distribution or reproduction is permitted which does not comply with these terms. 